\title{
Iglesia, justicia y liberación. La historia social y la obra de Jeffrey Klaiber S. J.
}

\section{Church, justice and liberation. The Church Social history the work of Jeffrey Klaiber S. J.}

Jesús A. Cosamalón Aguilar ${ }^{1}$

Pontificia Universidad Católica del Perú

\section{Resumen}

Una de las preguntas centrales en la obra intelectual de Jeffrey Klaiber S. J. es hasta qué punto las características internas de la Iglesia católica latinoamericana y peruana se relacionaron con las sociedades que las albergaban. Este artículo examina ese aspecto en profundidad y plantea que los trabajos de Klaiber constituyen una historia de la Iglesia "desde abajo". En ese sentido, se apunta que varias interpretaciones del historiador jesuita sobre la Iglesia latinoamericana están permeadas por categorías de la historia social. Particularmente, se detiene a observar la compleja relación entre la Iglesia, la sociedad y los Estados desde la colonia hasta los siglos XIX y XX, así como el rol de las organizaciones católicas en la defensa de los derechos humanos en las décadas finales del siglo XX.

1 Historiador, especialista en historia social de la ciudad de Lima colonial y republicana. Su campo de interés abarca la historia demográfica, mestizaje y grupos sociales, la historia de América colonial y republicana, la informalidad y la enseñanza de la historia a nivel escolar. Código ORCID: 0000-0001-6659-6570 Contacto: jcosamalon@pucp.edu.pe 
Palabras claves: Jeffrey Klaiber S. J., historia social, Iglesia católica, Perú

\section{Abstract}

One of the main concerns in the intellectual work of Jeffrey Klaiber S. J. is to what extent the internal characteristics of the Latin American and Peruvian Catholic Church were linked to the societies that professed this creed. The article examines this aspect in depth and states that Klaiber's texts constitute a history of the Church "from below". In this sense, the author points out that several interpretations of the Jesuit historian about the Latin American Church are permeated by categories of social history. In particular, the article highlights the complex relationship among the Church, societies, and the States from the colonial period to the $19^{\text {th }}$ and $20^{\text {th }}$ centuries, as well as the role of Catholic organizations' advocacy for human rights in the final decades of the $20^{\text {th }}$ century.

Keywords: Jeffrey Klaiber S. J., social history, Catholic Church, Peru

Introducción: Una historia desde abajo de las instituciones religiosas católicas

Analizar la obra de un ser humano tan singular como el padre Jeffrey Klaiber S. J. es una tarea que tiene características peculiares. Hombre de dos mundos, religioso dedicado a su labor pastoral en la Pontificia Universidad Católica del Perú (PUCP) y al mismo tiempo un académico acostumbrado a dialogar con personas de diversas creencias religiosas o sin ellas, su trabajo como historiador trató de conjugar ambos escenarios sin perder la razón de su vida: ser un religioso ca- 
tólico. Además, su vocación se desarrolló en un contexto de cambios trascendentales para la Iglesia mundial y latinoamericana, se formó como religioso bajo la enorme influencia del Concilio Vaticano II y la Conferencia del Episcopado Latinoamericano en Medellín (1968). Como jesuita, se enfrentó a la historia contemporánea con el objetivo claro de comprender el papel de la Iglesia como agente, o no, de cambio social y su relación con la sociedad y el Estado. Del mismo modo, se interesó por el proceso de evangelización desarrollado por su orden religiosa y la manera en que contribuyó con la mixtura cultural de la América hispana por medio de la "inculturación" que incorporó el cristianismo a las culturas locales sin destruirlas ni anularlas (Klaiber, 2007, p. 3)

Si bien su trabajo más temprano no estuvo dedicado a la institución eclesial, este se originó debido a su preocupación por la religión y su relación con la sociedad. De acuerdo con Ricardo Portocarrero (2015), su tesis de maestría dedicada a la relación entre las universidades populares y la aparición del APRA (Klaiber, 1968) surgió como efecto de la sorpresa que le produjo la importancia de ese partido, al mismo tiempo que evidenciaba la relevancia de la religión en la vida y política peruana. La Iglesia, aun cuando no le cerró la puerta al APRA, mantuvo una relación tensa con el partido. Los rasgos mesiánicos del liderazgo de Víctor Raúl Haya de la Torre y los elementos fascistas del partido convirtieron a ese movimiento en competidor de la Iglesia ${ }^{2}$. La institución eclesial en ese tiempo se encontraba entre varias tensiones, el marxismo, el APRA, las élites y las fuerzas armadas (Klaiber, 2000, p. 93). Luego de ese trabajo, su tesis doctoral Religion and Reform in Peru, 1824-1945 (1976), sí abordó uno de los ejes fundamentales de su labor como historiador: la historia de la Iglesia peruana y su relación con

2 Sobre la figura de Haya de la Torre, véase Klaiber (2004a); sobre los rasgos mesiánicos, véase Klaiber (1980, p. 185) y (2005b). 
los procesos de cambio, con especial referencia a la acción de las jerarquías y de las élites.

Si bien Klaiber no es percibido como un historiador social, sino como un intelectual dedicado a la historia de la Iglesia católica y de la política peruana del siglo XX, desde su ángulo incluyó la perspectiva social al sobrepasar los límites de la mera historia institucional. Sus textos no son solo un recuento, ampliamente documentado, de la vida de la Iglesia desde su llegada a América Latina hasta casi el presente. La novedad de su enfoque radica en las preguntas con las cuales se acercó a la historia de la institución, algunas de ellas no explícitas, pero fácilmente discernibles a partir de sus temas de investigación. Por ejemplo, se preocupó por reconocer hasta qué punto las características internas de la Iglesia se relacionaron con la sociedad que la albergaba, aun cuando los religiosos y religiosas no provenían del entorno local, como ocurrió durante la colonia y se repitió en la segunda mitad del siglo XX. Esta pregunta es importante, porque de acuerdo con su interpretación, Klaiber establece que no solo la institución se encontraba dividida social, cultural y políticamente, sino que esto era un reflejo bastante directo de las fracturas de las sociedades latinoamericanas desde la época colonial y, lamentablemente, hasta el presente.

Desde esa perspectiva, la actitud ambigua de la Iglesia ante las injusticias, violaciones de derechos humanos (DH), dictaduras y otros males de nuestro continente, no es privativa de ella, es el resultado de las mismas divisiones que tiene la sociedad. Esto no significa que Klaiber justifica o avala los hechos concretos por los cuales la Iglesia dejó de cumplir su papel de defensa de la vida y dignidad humana; por el contrario, es claro al señalar esas debilidades, pero las intenta comprender dentro del contexto de cada época, colocando por delante su labor como historiador antes que la de censor moral o religioso. 
Por esa razón, su trabajo como historiador de la Iglesia es el equivalente a una historia desde abajo, dentro de la institución. Si consideramos que esta es una institución de corte vertical, lo usual era elaborar una historia a partir de las decisiones y acciones de las jerarquías mejor documentadas y consideradas representativas de la oficialidad de la Iglesia. Sin embargo, Klaiber intenta recuperar la acción del clero secular y religioso, recogiendo y analizando la vida y hechos de múltiples personajes, especialmente durante el siglo XX, algunos de ellos silenciados u ocultados por la historia oficial por su radicalismo de derecha e izquierda. En ese sentido, se trata, como el subtítulo de una de sus obras fundamentales, de una historia social de la Iglesia.

Esta preocupación por la relación Iglesia-sociedad desde dentro de la institución no se restringió a la Iglesia, se extendió a la relación religión-justicia. Sin duda, este tema es una derivación de la anterior preocupación y se explica por el contexto en que se formó Klaiber como religioso y como intelectual. Hombre nacido durante la Segunda Guerra Mundial (1943-2014), el padre Klaiber fue parte de la generación de religiosos que fueron testigos y partícipes de la Iglesia preconciliar. Ingresó al seminario jesuita en 1961 y se ordenó en 1974, durante esos años la Iglesia sufrió cambios profundos por efecto del Concilio Vaticano II y los concilios latinoamericanos $^{3}$. Entre esas transformaciones, se pueden citar por su influencia en él como religioso y como intelectual, la preocupación por el mundo "real", la injusticia, la pobreza y la discriminación. Al mismo tiempo, la Iglesia adoptó una postura más activa con respecto a la política y crítica social, tanto de la oficialidad como de los laicos. En ese escenario, el padre Klaiber desarrolló su labor de historiador, tomando como base su reflexión desde el punto de vista de la fe para analizar

3 Sobre el contexto social y eclesial del Concilio, véase Klaiber (2012). 
la historia peruana y algunos de sus procesos importantes. Esto no significó, ni por asomo, una actitud complaciente y militante ciega con respecto a la historia de la Iglesia. Su enfoque fue tomar como punto de partida las preocupaciones contemporáneas de la Iglesia para acercarse a la historia. Su fe no fue el punto de llegada de su historiografía, fue la linterna que lo guio en sus grandes preguntas como hombre de Iglesia e intelectual, simultáneamente.

Este punto de partida conciliar explica, al menos en parte, su preocupación, rápidamente desarrollada en su historiografía, por la injusticia, la discriminación, la pobreza, el cambio social, los DH y la democracia. Klaiber fue testigo de excepción de los grandes cambios de los años sesenta, su espíritu revolucionario, el retorno del conservadurismo de los setenta, la violencia y la lucha por el retorno a la democracia. Era hasta cierto punto natural que sus preocupaciones historiográficas reflejen esos problemas junto con sus inquietudes por el papel de la Iglesia en todos esos hechos. Esta relación entre la historia de la Iglesia y la sociedad se debe a otro contexto contemporáneo: la consolidación de la historia social.

La vida de Klaiber coincidió con el surgimiento de la historia social como disciplina. En 1955 se organizó el Congreso Internacional de Ciencias Históricas de Roma, en esa reunión el historiador francés E. Labrousse propuso que la historia económica, reconocida como un campo de investigación, debería complementarse con el estudio de los grupos sociales, como la burguesía francesa. Durante la doble formación como religioso e historiador del padre Klaiber se llevó a cabo el primer congreso dedicado exclusivamente a la historia social en Saint-Cloud (Francia) en mayo de 1967. Ese mismo año se fundó la revista Social History (1967), en cuyo primer número Werner Conze, historiador alemán, definió su campo como el estudio de las estructuras sociales y estableció un 
vínculo con la sociología, sin determinar las diferencias entre una y otra.

A mediados de la década de 1950 y principios de la de 1970 se perfiló mejor el campo de la historia social. E. J. Hobsbawm (1988 [1970]) definió su campo como la disciplina interesada en los grupos sociales, sus estructuras internas y jerarquías, y el reconocimiento de sus relaciones con otras áreas de la sociedad. Como se puede apreciar, la obra del padre Klaiber dedicada a la Iglesia cumple esa definición. En sus páginas, encontramos una gran preocupación por estudiar a la institución como parte de la sociedad, ni por encima ni por debajo de ella.

\section{La historia social de la Iglesia}

Son dos los temas que me interesa destacar, ambos relacionados entre sí. En primer lugar, su preocupación por la historia de la Iglesia católica peruana y latinoamericana, estudiada desde la óptica de su papel en la sociedad y su desarrollo como institución con influencia en los actores sociales. En segundo lugar, la preocupación por la justicia desde el ángulo de lo social, a partir de las prácticas de la Iglesia y su relación con los procesos de cambio eclesiales y civiles en defensa de los DH apoyadas abiertamente o indirectamente por ella.

En el caso de la Iglesia peruana, sin duda su obra mayor es $\mathrm{La}$ Iglesia en el Perú. Su historia social desde la Independencia ${ }^{4}$. En ese trabajo desarrolla una mirada de larga duración acerca de la institución de la cual fue parte y aplica una característica usual de su método: abarca el tema hasta casi la víspera de la edición del texto. La primera edición (1988) cita trabajos y

4 El libro cuenta con varias ediciones, en este caso, empleo la tercera de ellas (1996). 
testimonios hasta el año 1986, lo que rompe la idea de la historia como una disciplina que solo debe abordar temas distantes en el tiempo. Por el contrario, su trabajo se caracterizó por ser siempre muy contemporáneo. El estudio de la Iglesia peruana fue la base de su reflexión para comprender el desarrollo y acción de la institución en la América Latina del siglo XX. Como se puede notar en las páginas que dedica al Perú, uno de los ejes de su reflexión es la relación de la Iglesia con la sociedad y la manera en que se fue involucrando con los problemas de ella. Un segundo trabajo póstumo y destinado a la difusión es Historia contemporánea de la Iglesia Católica en el Perú (2016), que amplía algunas de las ideas esbozadas en su libro de 1988.

En esta historia de larga duración Klaiber destaca los cambios internos en la Iglesia y su relación con la sociedad. Si bien esto podría parecer una verdad evidente, su respuesta dista de ser simple. Se concentra en dos factores trascendentales: la composición social de los religiosos y religiosas, al mismo tiempo que establece los mecanismos concretos por los cuales la Iglesia adquirió las características del entorno social en que se desarrolló. De acuerdo con su interpretación, la Iglesia colonial fue española, criolla y no misionera; mientras que la actual es misionera y con una gran presencia extranjera, al menos hasta fines del siglo XX. Reconoce en su investigación que la Iglesia no es inmune a su entorno social y, a veces, se le hace responsable de problemas que son de la sociedad antes que de la institución: "muchos de los problemas que afronta hoy la Iglesia son consecuencia no necesariamente de ciertas decisiones erróneas adoptadas por la propia Iglesia, sino más bien del tipo de sociedad en que se encuentra" (Klaiber 1996, p. 22). También reconoce que ella es una suerte de mini modelo de la sociedad que replica sus jerarquías, por ejemplo, en el tiempo colonial "había un clero alto y un clero bajo, criollos e indios, ricos y pobres" (1996, p. 36). Estas ideas se reflejan mejor en su estudio de la orden jesuita en América 
Latina, en el cual acepta que los jesuitas estuvieron entre los grandes propietarios de esclavos, mano de obra fundamental de sus plantaciones (2007, pp. 8-9).

Aunque en la república la Iglesia trató de acabar con la práctica de excluir a mestizos e indios del sacerdocio, de acuerdo con Klaiber, la sociedad se impuso sobre ella y mantuvo esa política. Así, surgieron dos cleros: por un lado, "un clero mejor formado y culto, proveniente de las clases medias y altas o del extranjero; por el otro, un clero de clase popular o de provincia, con menos formación y con menos prestigio que el otro" (1996, p. 36). Estas características se replicaron en toda América hispana y tuvo gran influencia en los conflictos sociales del siglo XX (1997a).

Su definición de la estructura social de la Iglesia es importante; el resultado de este tipo de clero diferenciado por clases dio surgimiento a tres tipos de Iglesia, cada una con características sociales diferentes. Esto se puede ver mejor en las ciudades: en el centro, la Iglesia es más tradicional; en los barrios acomodados es más moderna, y en los pueblos jóvenes es popular. "La así llamada «Iglesia popular» no es únicamente un movimiento teológico, sino un hecho social; los cristianos que la conforman pertenecen a las clases económicas más pobres". Este apunte de Klaiber es fundamental, pues reconoce que la base social de los movimientos teológicos, como la teología de la liberación, no son solo un recurso intelectual, "son, más bien, realidades impuestas por la sociedad en la que existe la Iglesia que condicionan su comportamiento y limitan sus posibilidades de actuar" (1996, p. 36) ${ }^{5}$.

Una de sus preocupaciones intelectuales fue comprender las razones por las que la Iglesia fue poco capaz de atraer a los sectores populares al estado eclesiástico. Encuentra que la

5 Véase también Klaiber (1980, pp. 231-236). 
institución históricamente se empeñó en mantener becas de estudios en los seminarios para los más pobres, pero el límite más grande provenía de la sociedad misma. Los altos niveles de analfabetismo, más el hecho de que la educación superior estaban muy lejana de las mayorías, fueron poderosas razones por las que los seminarios continuaron poblados por los hijos de las élites, lo que formó hasta el siglo XX un sacerdocio de clase media y alta. Una crítica importante que se hace a la Iglesia es que la educación que administraba estuvo dirigida a las élites, lo que Klaiber denomina "colegios clasistas" (1996, p. 239). Aunque algunas órdenes religiosas se dirigían a las clases medias populares (Salesianos, La Salle), paulatinamente terminaron más relacionados con las clases altas. Otras órdenes mantenían junto con sus colegios de élite otros para los pobres, pero perduró una imagen de la educación católica como elitista ${ }^{6}$. Por ejemplo, uno de los colegios para la clase alta, recomendaba que las nińas sean acompańadas por personas de su servicio (1996, p. 240). Además, en la formación del clero pesaron los modelos occidentales. Las palabras de Monseñor José Dammert lo reconocen con claridad al afirmar que en los seminarios parece que se forma a religiosos "con métodos y libros aptos para formar párrocos rurales italianos, franceses o españoles; al salir del seminario para ser el joven sacerdote destinado a la cura de almas en una parroquia apartada de los Andes, se encontraba que el 90\% de lo que había aprendido no le servía y al desechar lo inútil con frecuencia arrojaba también lo bueno" (Klaiber, 1996, p. 89). Por último, la vida de los sectores populares, tan lejos de la dignidad humana, causaba estragos de todo tipo en los habitantes de las sierras y ciudades del Perú, alejándolos de la posibilidad de iniciar una vida religiosa.

6 Esto se refleja en la influencia de la educación en el proceso de la independencia, pues en los colegios católicos estudiaron una buena cantidad de líderes de ese tiempo (Klaiber 1980, pp. 23-34). 


\section{Sociedad, Estado e Iglesia coloniales}

La relación Iglesia-sociedad es fundamental para comprender su historia. En ese sentido, Klaiber tiene apuntes interesantes con respecto a la sociedad colonial y la Iglesia. Considera que esta tiene una "tradición distinta", forjada con la visión jerárquica y paternalista europea, "que regía las relaciones entre las clases sociales y la omnipresencia de la Iglesia en todas las esferas desde las más altas hasta las más bajas" (1996, p. 22). Pero, junto con ella, se desarrolló una sociedad multirracial,

que selectivamente asimilaba ciertos elementos y ciertas maneras
de ser típicos de la madre patria, aunque rechazaba otros. No fue
precisamente una sociedad feudal ni capitalista, aunque poseía
elementos de los dos sistemas. Muchos autores han convenido
en describirla como una sociedad "corporativa», un modelo teó-
rico que tiene la ventaja de incluir categorías tan disímiles como
«raza», "casta», «clase» y «estamento». (1996, p. 23) ${ }^{7}$

Klaiber no rehúye el debate acerca de los conceptos de la historia social, más bien, opta por una visión ecléctica muy acorde con su personalidad y trata de armonizar visiones distantes. A pesar de esa elección, válida intelectualmente y con espíritu crítico indica que en la realidad no había ciudadanos y se impuso una política jerárquica y paternalista expresada en la conocida dos repúblicas, de españoles y de indios. En su posición acerca de la realidad colonial reconoce que el sistema estuvo organizado para explotar la mano de obra y nunca la república de los indios se igualó con los espańoles o criollos, "antes bien, los subordinaba a los dos últimos" (1996, p. 24). Su percepción de la sociedad es que en las jerarquías se confundían factores raciales, de clase y de estatus ${ }^{8}$.

7 Otro texto que discute este tema es Klaiber (1988a).

8 Hay que recordar que en los años ochenta aún se utilizaba la noción de raza, pero la diferencia es que Klaiber intuye que esta funcionó junto con otros factores. 
Esa explotación y abuso de poder se agravaban por el racismo y clasismo de la sociedad colonial; un ejemplo de la permanencia de esos mecanismos fue el enganche de trabajadores indígenas durante el siglo XX (Klaiber 1988, p. 193). Asimismo, reconoce que el sistema colonial incluyó una buena dosis de paternalismo, en el cual las autoridades, desde el rey, actuaron bajo el clientelismo vertical con una alta dosis de corrupción, favoritismos y sobornos. La Iglesia reprodujo ese paternalismo; los curas actuaban como patrones frente a sus feligreses y exigían estipendios y beneficios por sus servicios, especialmente porque sus labores como religiosos no siempre eran el resultado de sus verdaderas vocaciones (1996, p. 36). Finalmente, "si bien existían clases sociales, no existía una conciencia de clase en el sentido moderno. La conciencia fundamental de todos, ricos o pobres, peninsulares, criollos, indios y esclavos, fue la de pertenecer a un "cuerpo" o a un pueblo o a una raza” (Klaiber, 1988, p. 181).

Esa sociedad no pudo ser transformada por las reformas borbónicas ni el liberalismo posterior, la sociedad continuó siendo colonial en su composición y estratificación, especialmente porque "el liberalismo fue la bandera ideológica de una élite intelectual muy reducida: sacerdotes, abogados y propietarios de las capas medias" (1996, p. 27). La sociedad de la república inicial mantuvo el paternalismo, personalismo y la mentalidad corporativa, los cuales son males que reaparecieron en diversos momentos de nuestra historia. Incluso un régimen tan lejano en el tiempo de la época colonial, como el del general Juan Velasco Alvarado, tuvo, de acuerdo con Klaiber, rasgos corporativos, reflejados en la idea de que la sociedad debería funcionar en "armonía bajo la tutela del Estado con el fin de lograr una meta ideal común. El Estado (o las fuerzas armadas) asume el papel de tutor, guía y coordinador frente a las otras partes; organiza y dirige la participación de los partidos, los sindicatos y las distintas clases sociales con el fin de minimizar los antagonismos y las tensiones" 
(1996, p. 27). Es muy interesante que Klaiber, gracias a su conocimiento del mundo colonial y republicano, es capaz de percibir las constantes de nuestra historia en cuanto a la relación entre la sociedad, el Estado y la política. Por esa razón, compara el régimen militar caracterizado por el SINAMOS (Sistema Nacional de Movilización Social) con los Borbones, quienes pensaban trabajar por el pueblo sin el pueblo (Klaiber, 1988, p. 183).

En ese sentido, Klaiber define un legado colonial diferente del que surgió con el trabajo de los esposos Stein (1974). En su obra, Klaiber señala una herencia consistente en una Iglesia con una vida institucional débil y muy poco autónoma, demasiado dependiente de la Corona, luego del Estado, e impuesta desde arriba a la sociedad, con privilegios y sueldos provenientes del poder estatal, lejos del mito de una Iglesia todopoderosa. Incluso existía una competencia entre criollos y peninsulares por los cargos, tanto entre los religiosos hombres como mujeres.

\section{La Iglesia en los tiempos republicanos}

La Independencia hizo recrudecer las debilidades de la Iglesia. Las expulsiones de curas y obispos y las fricciones con el nuevo Estado frenaron su autonomía y se refugió en la relación con el Vaticano y el papado para sostenerse. Sin embargo, la sociedad peruana mantuvo su relación con ella por medio de las cofradías y hermandades, más que con la vida parroquial. Esas asociaciones reproducían las jerarquías coloniales, pues existían cofradías para cada estamento social. Por eso, Klaiber afirma que la Iglesia no era una institución unida y uniforme, contrariamente a la imagen de la mayoría de los estudios previos. La masa de fieles estaba organizada en pequeños núcleos; la mayoría de ellos, sobre todo en las zonas rurales, en contacto con un clero de escasa formación y con 
prácticas prohibidas por la Iglesia. Klaiber menciona temas que luego serían más frecuentes. Reconoce que el machismo era general en la sociedad, pero con el apunte de que la Iglesia actuaba de forma clasista, "en una sociedad que margina a la mujer pobre y sobreprotege a la mujer de clase alta. La moral social de la Iglesia se estrella con una sociedad tradicional que propicia la inestabilidad y el machismo" (1996, p. 39).

Su sentido del devenir histórico le permite sintetizar con eficacia y sencillez el derrotero de la Iglesia desde el periodo colonial, posteriormente precisadas en su libro acerca de la Iglesia latinoamericana en el siglo XX. Aplicando la noción weberiana de legitimidad, establece que la Iglesia gozó de esa característica por el papel que cumplió la religión y no tanto por su relación con el Estado. Su presencia en todos los grupos sociales y a lo largo del territorio le otorgó reconocimiento, al mismo tiempo que confirió cierto estatus a los indios, negros y mestizos. Como señala Klaiber, "aun dentro de ese orden antidemocrático y paternalista, la Iglesia - y la religión en general - ofrecían espacios (la vida religiosa, las misiones, las cofradías, etc.) en los que las clases populares podían encontrar protección y gozar de cierto estatus social" (1997a, p. 17).

Durante la etapa republicana (siglos XIX y XX), la Iglesia mantuvo sus privilegios a pesar de que los conflictos con el Estado afectaron a la jerarquía eclesiástica; incluso el clero mantuvo cierta uniformidad social (Klaiber, 2016, p. 16). Las políticas liberales no fueron tan consistentes hasta 1855 , especialmente por la ausencia de una base popular. Recién hacia mediados del siglo XIX con el triunfo de los liberales con el general Ramón Castilla, se intentó aplicar algunas reformas, pero fueron rechazadas por buena parte de la población y se logró mantener el statu quo con la Constitución de 1860 hasta 1930. Entre fines del siglo XIX y principios del siglo XX aparecieron movimientos radicales positivistas $\mathrm{y}$ 
anarquistas que amenazaron la posición de la Iglesia, lo que llevó a que los miembros más conservadores de la élite intentaran defenderla por medio de partidos políticos, la fundación de colegios, la llegada de nuevas órdenes, el apoyo a algunos presidentes y la fundación de la Universidad Católica en 1917. Ese enfrentamiento con corrientes radicales dividió a las élites, pero tuvo mayor efecto entre los hombres y dejó a las mujeres las prácticas públicas del catolicismo (1996, p. 45). La Iglesia no logró cohesionar a la nación, especialmente por su dependencia del poder político, “inmovilizada en una pastoral tradicional que ya no atraía a muchas personas, especialmente a los hombres con una mentalidad más moderna y más crítica frente al orden establecido" (1996, p. 46). Además, entre mediados del siglo XIX y principios del siglo XX llegaron al Perú diversas congregaciones religiosas dedicadas a fundar obras de asistencia social, muchas de ellas femeninas: Las Hijas de la Caridad, las Hermanas de San José de Cluny, las Hermanas del Buen Pastor, las Hermanas de San José de Tarbes, las Hermanitas de los Ancianos Desamparados, las Siervas de María, las Mercedarias Torbes, las Franciscanas de la Inmaculada Concepción; mientras que las de varones, como la congregación de los Camilos, fueron menos numerosas (2016, pp. 48-49).

Un cambio importante se dio cuando se publicó la encíclica Rerum novarum en 1891, la cual coincidió con la eclosión del movimiento obrero e indigenista en el Perú. La propuesta de la Iglesia era establecer una sociedad alternativa al comunismo y el capitalismo liberal, una tercera vía que fue aceptable para las clases medias y algunos sectores de la clase alta no vinculados a las oligarquías costeńas. Esos grupos manifestaron su preocupación por los trabajadores explotados e indios, pero sin cambios violentos y conservando valores tradicionales como la familia, la propiedad y la religión. Los católicos militantes defendían las reformas, pero al mismo tiempo evitaban la lucha entre las clases. Esto llevó a la fundación del 
Partido Conservador en el Cusco (1896) y el Partido Católico en Arequipa (1913) (Klaiber, 1996, pp. 130-131) ${ }^{9}$. El significado que le otorga Klaiber es de cristianos que buscaban mantener no solo los valores de la Iglesia, sino sus intereses y privilegios, movilizando a sus fieles en una causa religiosa y política. Su objetivo era construir una sociedad opuesta al liberalismo, fortaleciendo su vínculo con Roma y reforzando su relación con el Estado. Por estas razones la institución fue percibida como conservadora o tradicionalista. Este fue uno de los motivos por los que las mujeres se convirtieron en las defensoras más fuertes de la Iglesia católica, debido a que "el liberalismo adquirió ciertos matices "machistas"” (1996, p. 116). Ese cristianismo fue definido por Klaiber como de fieles "militantes". Es interesante que Klaiber le dé un giro al concepto "militante" (1996, p. 100), usualmente asociado con los partidos políticos y con los católicos de las décadas de 1960 y 1970 , quienes desarrollaron experiencias políticas desde su ser católico.

Esos movimientos fueron mucho más conscientes de la importancia social de la Iglesia y debatieron con el marxismo y el aprismo en cuanto a la sociedad y la política. Sin embargo, a pesar de sus méritos, su capacidad de movilizar masas era escasa. Era fundamentalmente un movimiento de élites, sin tocar la religiosidad popular ni llegar a disputarle el terreno al APRA ni su anticlericalismo (Klaiber, 2000, p. 88) ${ }^{10}$. Sus limitaciones eran claras, no renovó la teología y se concentró en las prácticas piadosas tradicionales, sin motivar la participación de los laicos en la Iglesia. Incluso, como señala Klaiber, frente al creciente indigenismo, reforzaron su situación de clase enfatizando el hispanismo franquista, como fue el caso de José de la Riva Agüero. Uno de los puntos altos de ese proceso fue la

9 Véase también Klaiber (1983b y 1983c).

10 Véase también el análisis de Klaiber de la protesta contra la consagración del Perú al Corazón de Jesús (1980, pp. 150-153). 
creación de la Unión Popular, liderada por el vicerrector de la Universidad Católica, Carlos Arenas y Loayza, presidente de la Unión Católica de Caballeros y Damas, asociación fundada en 1886. Los objetivos de la Unión eran enfrentar a la tendencia anticlerical presente en las reformas aplicadas por Luis Sánchez Cerro y la Constitución de 1933. En ellas se aprobó la obligatoriedad del matrimonio civil y el divorcio absoluto. Sus inicios fueron complicados, el partido fue perseguido acusado de ser parte de una conspiración comunista y se detuvo a sus miembros laicos y religiosos. A pesar de su poca duración, sus propuestas reconocían la necesidad de una serie de reformas, como la intervención del Estado en beneficio de la sociedad, la nacionalización de fuentes de producción, del suelo y del subsuelo y el proteccionismo económico. Abogaron por el salario mínimo, el seguro social de vejez, el seguro médico y de accidentes, el reconocimiento de los sindicatos y la necesidad de garantizar el mejor desarrollo de los indígenas por medio de la devolución de las tierras usurpadas y de la educación. A pesar de este programa bastante progresista, sus dirigentes representaban fundamentalmente a los sectores de clase alta, especialmente a los hacendados. De acuerdo con Klaiber, "es difícil no llegar a la conclusión de que, virtualmente, la UP era el partido de los hacendados" (2016, p. 78). Según su interpretación, las clases sociales que se identificaban más con la Iglesia y la defendían eran "en primer lugar los grupos sociales que buscaban orden y que añoraban los valores tradicionales como una manera de asegurar el bien común. Entre los amigos de la Iglesia estaban ciertos sectores de la clase media, sobre todo de provincias, ciertas familias de vieja tradición y, sobre todo, la inmensa mayoría de los sectores populares" (Klaiber, 2000, p. 89).

En esa época, en las zonas rurales del interior se consolidó la relación cura-hacendado gamonal, especialmente por los vínculos familiares entre ambos. Entre los dos personajes y sus entornos familiares existía una mayor horizontalidad 
que con los campesinos indígenas. La Iglesia se fijaba especialmente en las facilidades que los propietarios daban a la institución para las misas dominicales y la labor misional, lo que mantuvo las estructuras paternalistas. Sin embargo, en algunos casos, los religiosos denunciaban la situación de maltrato a los indios, pero sin cuestionar el sistema de haciendas (Klaiber, 1996, p. 275). Así, en 1922 se organizó en el Cusco el Congreso de Acción Social, dentro del ambiente y enseñanzas de la Rerum novarum con el objeto de proponer soluciones en beneficio de los indios, trabajadores obreros y mujeres,

se propuso la creación de escuelas-talleres para los indios y la publicación de catecismos en quechua y aymara. En cuanto a los obreros, hizo un llamado en favor de la extensión de los círculos católicos de obreros a todas partes y la fundación de bibliotecas y de sociedades de ayuda mutua para la clase trabajadora. También recomendó la creación de ligas anti-alcohólicas para indios y obreros. (Klaiber, 1996, p. 277)

El congreso rechazó las propuestas radicales bolcheviques, socialistas y protestantes, sin enfrentar el problema de la propiedad y la explotación, contentándose con mantener las medidas de corte reformista e higienista. El sínodo posterior de 1923 muestra con claridad ese carácter reformista y paternalista. Se propuso

el matrimonio entre indios y blancos como una manera de evitar la lucha de razas. Asimismo, exhortó a los grandes propietarios que asumieran voluntariamente el patronato de sus propios indios pagándoles el justo salario y no obligándoles a trabajar más de lo que la salud permite. Finalmente, el Sínodo exhortó a todos, hacendados e indios a vivir en paz. (Klaiber, 1996, p. 279).

Esa actitud de la iglesia no fue popular entre los indigenistas. La institución carecía de las armas intelectuales y estaba presa dentro de los límites que la Rerum novarum preveía, la cual 
rechazaba las propuestas violentas y radicales. Además, los curas estaban emparentados con los hacendados y en muchas oportunidades ellos mismos percibían los beneficios del sistema de propiedad. Por último, los indios, quienes eran el grupo en discusión, no se encontraba representado en el sínodo. A pesar de esas limitaciones, muchos religiosos asumieron la defensa de los indios, por ejemplo, quienes fueron miembros de la Sociedad Amigos de los Indios o actuaron como mediadores en los conflictos. Sin embargo, su papel más frecuente fue de defensora y legitimadora del orden.

En 1935, esa Iglesia "militante" fue dejada atrás por la fundación de la Acción Católica luego del Congreso Eucarístico de ese ańo, la cual permitió la movilización de los católicos en el espacio público. A partir de ese movimiento surgieron otros, como la Juventud Obrera Cristiana (JOC) ${ }^{11}$, la Unión Nacional de Estudiantes Católicos (UNEC) y el Movimiento Familiar Cristiano, entre otros (Klaiber, 2016, p. 56). Ese movimiento católico fue la fuente de vocaciones de gran importancia en la Iglesia peruana, como José Dammert, Luis Vallejos, obispos de Cajamarca y Cusco, respectivamente; también del teólogo Gustavo Gutiérrez y del obispo de Huancayo, Eduardo Picher (pp. 58-59). La relevancia de Acción Católica tuvo su cénit en las semanas internacionales organizadas con sus homólogas de Bolivia y Chile en 1945 y 1949. Luego de ambas reuniones, sin resultados satisfactorios para sus representantes, los miembros de la sección peruana organizaron con el obispo de Talca (Chile), Manuel Larraín, la tercera semana en Chimbote (1953), lo que inició una nueva fase del movimiento, mucho más dedicada a

11 Ese movimiento tuvo como antecedente la creación de la Sociedad de Obreros del Sagrado Corazón (1931) y la Federación de Sociedades Obreras Católicas (1932) (Klaiber, 2016, p. 63). El religioso de importancia fundamental para estudiar este proceso es Amelio Plasencia, quien creó las primeras células de la JOC en el Perú en los años treinta. 
temas sociales. A partir de ese momento, diversos integrantes llegaron a la conclusión de que debían dedicarse más a la política si deseaban transformar la realidad. Su decisión derivó en la fundación del Partido Demócrata Cristiano (1956) y en la cada vez mayor independencia de la UNEC (p. 61).

\section{Una nueva reforma eclesial}

La Iglesia se modernizó a partir de 1955, cuando los obispos de América Latina se reunieron en una conferencia continental en Rio de Janeiro, que inició el cambió de actitud de la Iglesia frente al mundo secular, lo que coincidió con los cambios de la institución a nivel global. Ese célebre "aggiornamento" exigió reformas de todo tipo, incluidos los cambios en la liturgia para acercarla más a los fieles. Esas transformaciones se enfrentaron a la escasez de vocaciones sacerdotales, lo cual derivó en el aumento de la presencia de órdenes religiosas de origen anglosajón y europeo no hispano ${ }^{12}$. Paralelamente, fue fundamental el cardenal Juan Landázuri, quien inició y desarrolló un pujante proyecto de construcción de parroquias en las zonas conurbanas de la capital para atender la creciente necesidad de los habitantes de la capital ${ }^{13}$. En 1957, el cardenal anunció la creación de la Misión de Lima, con el objeto de atender espiritual y materialmente a los habitantes de los márgenes de la ciudad. Como es conocido, desde mediados del siglo XX la población de Lima creció rápidamente; en 1940 tenía cerca de 850.000 habitantes, mientras que en 1962 había más que duplicado su número

12 Esa fue una de las preocupaciones más importantes de su trabajo. Las primeras páginas dedicadas a la Iglesia republicana se concentran en la escasez de religiosos y la situación del clero en las primeras décadas de nuestra historia independiente (Klaiber, 1981 y 1996, pp. 65-68).

13 Véase Klaiber (1997b) para el contexto de la década. En Klaiber (1999) desarrolla específicamente el contexto de la Iglesia en los años cincuenta. 
a cerca de 1.900 .000 personas; en 1972 esa cifra se elevó a cerca de 3.500.000 y a alrededor de 4.800.000 en 1993. Esa expansión demográfica se asentó principalmente en las zonas periféricas, donde se hicieron habitables terrenos eriazos, cerros y arenales en un esfuerzo humano que llamó la atención de la Iglesia por el sufrimiento y la pobreza que caracterizaban esos espacios.

Un hito importante en esta historia social de la Iglesia es la publicación en 1958 de la Carta pastoral del Episcopado Peruano sobre algunos aspectos de la cuestión social en el Perú. En ese documento se muestra una posición bastante más crítica de la realidad:

La afluencia de riqueza se ha concentrado a menudo en pocas manos ya se trate de la agricultura, la industria y el comercio, y se ha acentuado la contraposición entre los que tienen la riqueza y los que sólo tienen su trabajo. En tal forma los bienes de este mundo están desigualmente repartidos, de manera que se originan conflictos, los que se acentúan cuando las contingencias naturales de sequías o plagas u otros acontecimientos telúricos agudizan la necesidad de quienes no tienen reservas. La inestabilidad económica de nuestros tiempos, además se manifiesta en el alza del costo de vida, el cual aumenta la preocupación de quienes no tienen para subsistir sino un haber que permanece inalterable y no se ajusta lo suficientemente a las necesidades.

Sin entrar a describir esta compleja realidad, es un hecho que un gran número de quienes están desprovistos de los bienes suficientes, coincide con la población indígena que vive en las serranías, con obreros ocupados en industrias extractivas o manufactureras, y con jornaleros de algunas zonas agrícolas. No queremos dar a nuestras afirmaciones una generalización imprudente e injusta, pero nadie puede negar la gran pobreza rayana casi en la miseria, y el sentido de depresión en que viven muchos de nuestros hermanos en la Sierra. Nadie puede negar la triste condición de los indígenas emigrados de sus tierras y asalariados en muchas de las haciendas a veces por cortos períodos de tiempo, sin encontrar 
ningún estímulo que les ayude en la tristeza de su soledad lejos del terruño. Este asunto pertenece, como toda cosa auténticamente humana, al doble mundo del espíritu y de la materia. La Iglesia Santa debe hacer oír su palabra, no para resolver los aspectos concretos de orden técnico, económico o estadístico, sino para iluminarlos con la luz de la Revelación y de la conciencia humana.

La interpretación de Klaiber del documento enfatiza el llamado de los obispos a la justicia social; además, las autoridades religiosas elogiaron las cooperativas parroquiales fundadas en Puno y Lima, como modelos de asociación libre. Por último, denunciaron las malas condiciones de vida en las barriadas limeñas y convocaron a la Primera Semana Social en 1959. Esa reunión hizo tomar conciencia de la necesidad de aplicar la reforma agraria dentro de la Iglesia, la cual se desarrolló en Cajamarca y Cusco.

Ese proceso social coincidió con la demanda eclesial de acercar la Iglesia a la sociedad y sus problemas, exigiendo una toma de conciencia y una renovación de la institución. Así, como seńala Klaiber, se produjo un proceso de modernización en doble dirección; por un lado, significó una transformación de la imagen pública de la Iglesia y por el otro, un reconocimiento de los graves problemas que enfrentaban las grandes mayorías de católicos peruanos. Esto se tradujo en una renovación de la liturgia y de la pastoral. Ese nuevo escenario fue el contexto de la aparición de nuevos movimientos de laicos formados en la nueva cultura eclesial, la cual inclu136 yó la participación política, como fue el caso de la Democracia Cristiana ${ }^{14}$. La intención de la Iglesia y de los laicos era desarrollar una alternativa católica a la creciente importancia

14 En América del Sur, uno de los primeros países en desarrollar el socialcristianismo fue Chile con el Partido Conservador (1934). Las figuras fundamentales de ese movimiento fueron el cardenal Raúl Silva Enríquez y el político Eduardo Frei Montalva (Klaiber, 1997a, p. 81). 
del marxismo y sus partidos, pero que simultáneamente fuera consciente de la pobreza e injusticia que los rodeaban. La preocupación por el subdesarrollo y la calidad de vida de los habitantes más pobres de América Latina y el Perú sobrepasó, pero también potenció, la labor de caridad de la institución. De esa manera, lo social y lo cristiano se unieron en una sola palabra: "socialcristiano" (Klaiber, 1996, p. 51) ${ }^{15}$. Fruto de ese esfuerzo fue la citada Primera Semana Social de la Iglesia, celebrada por monseñor José Dammert, luego obispo de Cajamarca y uno de los impulsores de la pastoral campesina en el Perú, posición que se reiteró en comunicados de los obispos invitando a los cristianos a tomar "una mayor responsabilidad política con el fin de efectuar más cambios sociales" (p. 52). También es importante mencionar la fundación de la Comisión Episcopal de Acción Social en 1965, presidida por el obispo Luis Bambarén. Es importante señalar que esa relación de la Iglesia con el mundo campesino no fue tan frecuente en Sudamérica, uno de los casos relevantes es del de Paraguay y las Ligas Agrarias Cristianas de los años sesenta; otro es el conocido caso de los cristeros en México (Klaiber, 1997a, p. 162). En el caso paraguayo, las ligas animaron las tomas de tierras y la reforma agraria, razón por la cual fueron acusadas de estar infiltradas de comunistas.

Durante el siglo XX, especialmente después del Concilio Vaticano II, la Iglesia dejó de ser garante del poder para, por lo menos un sector de ella, dedicarse a cuestionar los sistemas políticos y económicos que sustentaban el poder de las élites. Hacia fines de los años sesenta, con el llamado de los obispos en la Conferencia de Medellín de 1968, la Iglesia dejó en claro su compromiso con

15 Un caso interesante, por el contexto revolucionario, fue el mexicano. Con la Constitución de 1917 se establecieron principios anticlericales y la reacción de los católicos y de los liberales anticatólicos fue extremadamente violenta, lo que desató la conocida guerra cristera (Klaiber, 2007, p. 219). 
la justicia y los $\mathrm{DH}$, legitimando los movimientos compuestos por campesinos, obreros, pobladores de favelas, villas miseria o pueblos jóvenes. En ese tiempo, la institución incorporó los ideales liberales de democracia y DH, acercándose a las luchas en favor de los derechos de las mayorías.

Como señala Klaiber, ese ambiente crítico socavó las bases de la Iglesia preconciliar e invitó a laicos y religiosos a ejercer una actitud más crítica y pluralista "y a que asumieran papeles de responsabilidad en la Iglesia y en el mundo" (1996, p. 52). Además, los cambios de los años sesenta, reflejados en el empuje de la Revolución cubana, las guerrillas y la esperanza de los cambios reformistas del gobierno de Fernando Belaúnde trajeron como resultado la exigencia de cumplir con la modernización al mismo tiempo que se cuestionaban las bases y resultados de la labor de la Iglesia.

Luego del golpe militar de 1968, que entre otras causas se produjo por el empantanamiento de las necesarias reformas, la tendencia crítica de la Iglesia peruana se profundizó por el empuje de las conferencias del episcopado latinoamericano (Medellín, 1968 y Puebla 1979); las cuales se interesaron en apuntalar una experiencia de fe desde América Latina. A diferencia de los contextos de Chile, Argentina, Brasil, entre otros, la Iglesia peruana se relacionó con un gobierno de militares progresistas que buscó apoyarse en ella. Por esa razón, su respaldo a los cambios fue fundamental y participó en la toma de algunas decisiones por medio de su endoso público. Incluso esos militares se encontraban cercanos a la Iglesia por medio del "catolicismo cultural" definido por Klaiber (1980, p. 196), consistente en una actitud de seguir los rituales católicos y de la religiosidad popular, al mismo tiempo que se critica la actitud de las jerarquías eclesiásticas, pero se les reconocía su importancia política. Otro conjunto de oficiales, más de clase media y alta, educados en colegios religiosos, compartían ideales con una mezcla de idealismo religioso 
y secular presentes en tres documentos: la Ley General de Educación, las bases ideológicas de la revolución peruana y los lineamientos de la política de población en el Perú (pp. 196-199).

Sin embargo, la profundidad de las transformaciones y su velocidad revelaron las fisuras internas de la institución eclesial. Mientras que un conjunto de religiosos y religiosas formaron la Oficina Nacional de Información Social (ONIS), influenciados por la teología de la liberación desarrollada por el padre Gustavo Gutiérrez Merino (Lima, 1928), otros sectores manifestaban su desacuerdo con ese radicalismo y se apoyaban en movimientos claramente más conservadores como el Opus Dei (España 1928, Lima 1953) y luego Sodalitium Christianae Vitae (Lima, 1971). Estos hechos muestran que la Iglesia también reaccionó de forma similar a la sociedad, dividiéndose en su apoyo o no a las reformas del gobierno militar.

Un tema fundamental de las reformas fue la educación. Klaiber se interesa por ella debido a su papel como herramienta de transformación de la realidad y sus vínculos con la Iglesia católica. La modernización de la educación se basó en la incorporación de nuevas ideas pedagógicas, como las del brasileño Paulo Freire acerca de la educación liberadora, de gran influencia en los cristianos progresistas, como los de la Unión Nacional de los Estudiantes Católicos, la Juventud Estudiantil Católica y Equipos Docentes del Perú. Ese proceso tuvo gran influencia en los estudiantes de la época, como indica Carlos Torres (1998-1999). Su foco era concebir la fe como un proceso de "liberación" de las estructuras injustas nacionales o internacionales y entendían la labor del cristiano como la concientización de los pueblos oprimidos a partir de una nueva pedagogía ${ }^{16}$.

16 Para un estudio más detallado de la izquierda católica, véase Klaiber (1980, pp. 223-230). 
Todas esas propuestas trajeron cambios fundamentales en la pastoral. Se creó un modelo de cristiano comprometido con los cambios, activo en esa lucha, que rechazaba el modelo tradicional "y poco crítico del cristiano 'pacífico'... el cristiano comprometido debería identificarse lo más posible con el pueblo 'oprimido' con el fin de concientizarlo, es decir, de ayudarlo a que tuviera más conciencia de sus derechos y de su dignidad humana" (Klaiber, 1996, p. 56). Pienso que estas afirmaciones se deben trasladar a su historiografía. Su derrotero muestra con claridad su preocupación intelectual coincidente con estos imperativos, como veremos en estas páginas.

Esa nueva perspectiva de vivir la fe se expresó completamente en el debate acerca de las reformas educativas de los años setenta. La pugna, a diferencia de otros casos, no fue entre un Estado que pretendía aplicar una educación laica y la Iglesia oponiéndose a ella, sino que se desarrolló en el interior de la institución eclesial, entre católicos a favor de las reformas y quienes, dentro de la Iglesia, se oponían a ellas. Los cambios planteados buscaban incorporar en un solo plan de educación a los colegios públicos y religiosos con el objetivo de reducir las diferencias sociales. Así, la Iglesia se vio atrapada entre aceptar la decisión del gobierno de promover la educación entre las clases media y baja o continuar con su tradicional apoyo a la educación de la clase alta (Klaiber, 1987b, pp. 33-34).

140

La educación privada religiosa tuvo un gran impulso desde 1962 gracias a una ley que permitía subvencionarla por el Estado, política ratificada por los militares desde 1968. Con esa política se produjeron dos escenarios, por un lado, favoreció el sostenimiento de los colegios fundados por las órdenes religiosas, pero, al mismo tiempo, les cortaba su autonomía al depender de fondos públicos. Además, una buena cantidad de colegios estatales eran dirigidos por religiosos (p. 36). Por otro lado, en el contexto de la época, caracterizado por 
el Concilio Vaticano II y Medellín, muchos religiosos apoyaban esos subsidios porque les permitía dedicar la educación a los sectores más pobres y acabar el elitismo del cual eran críticos.

Por esas razones, la Iglesia participó oficialmente en la discusión y redacción de la reforma educativa, por medio de los jesuitas Ricardo Morales y Romeo Luna Victoria, quienes con un grupo de intelectuales se encargaron de la reforma, inspirados por el pedagogo brasileño Paulo Freire. Esta garantizaba la educación religiosa basada en los nuevos principios del Concilio Vaticano II y Medellín, y expresados en la teología de la liberación. Esos cambios fueron rápidamente cuestionados y combatidos por representantes y padres de familia de los colegios religiosos, especialmente de la clase alta. El gobierno intentó negociar y consensuar los cambios, pero eso fue imposible por el ataque de los opositores a los cuadernos de religión para ser usados en las escuelas, a los cuales acusaban de estar contaminados con el marxismo e incitar a la lucha de clases; como consecuencia de esa denuncia, los colegios de la clase alta amenazaron con no iniciar el año escolar 1975. Esos conflictos no solo enfrentaron a algunas órdenes religiosas contra el gobierno, también entre los religiosos existió división en cuanto a las reformas (p. 41). Esos enfrentamientos se agravaron con las huelgas del Sindicato Unitario de Trabajadores en la Educación del Perú (SUTEP) entre 1978 y 1979; algunos colegios religiosos apoyaron las reformas, mientras otros se opusieron a ellas.

Otra consecuencia de las tensiones internas de la Iglesia fue la reorientación de una parte importante de los laicos hacia los partidos de izquierda, incluso con el apoyo de religiosos y religiosas. Por esa razón, la acción de la jerarquía fue percibida, en algunos casos, como más política que pastoral, como el caso del arresto del obispo Luis Bambarén luego de celebrar en 1971 una misa de apoyo a los invasores de los 
arenales, llamada luego Villa El Salvador. En esa celebración, el obispo aseguró que no eran invasores, sino "fundadores de un nuevo pueblo", y afirmaba que vivían un calvario semejante al de Cristo. Luego de ser detenido por el ministro del Interior general Armando Artola, el cardenal Landázuri y ONIS protestaron enérgicamente, lo que causó la renuncia del ministro (Klaiber, 1980, p. 213).

En ese sentido, la historia de los llamados pueblos jóvenes está indudablemente relacionada con la Iglesia. De acuerdo con Klaiber, de 136 parroquias de la Arquidiócesis de Lima en 1984, 22 se encontraban en pueblos jóvenes y 19 en urbanizaciones populares, lo cual llevó a que la institución reconozca esas zonas como un área pastoral distinta y nombraron a un obispo auxiliar. Los religiosos y religiosas que trabajaban en esos lugares tenían un carácter misionero y recibían la ayuda de subvenciones de instituciones extranjeras. Muchas de ellas funcionaron con actividades más allá de sus labores sacramentales y de auxilio espiritual e incluyeron servicios educativos y cursos para adultos, entre otras actividades. Una situación similar se vivió en la sierra sur, espacio con gran presencia de órdenes religiosas extranjeras.

Ese proceso dista de ser exclusivamente peruano. En Chile, donde tempranamente apareció el socialcristianismo, la Democracia Cristina se convirtió en el partido representativo de la Iglesia, a pesar de los esfuerzos del cardenal Silva Enríquez por mantener una distancia prudente del partido. Eduardo

142 Frei, líder de la DC, encabezó una serie de reformas en los años sesenta, como la primera reforma agraria y la nacionalización del cobre. Eso llevó a un proceso casi natural de radicalización de la iglesia chilena, que hizo demandas en favor de cambios sociales y económicos. A fines de los años sesenta el enfrentamiento entre los religiosos radicalizados y el cardenal era notorio, lo que llevó a la organización de la Sociedad Chilena de Defensa de la Tradición, Familia y Pro- 
piedad (1967), la cual denunció el radicalismo de los jóvenes. Su base se encontraba en la Universidad Católica y tuvieron un papel importante durante la dictadura del general Augusto Pinochet (Klaiber, 1997a, p. 84). Incluso durante la presidencia de Salvador Allende se formó el movimiento Cristianos por el Socialismo $(1971)^{17}$, liderado por el sacerdote jesuita Gonzalo Arroyo, quien criticó el conservadurismo de la Iglesia. Ese movimiento se fue radicalizando y fue oficialmente prohibido por las autoridades católicas en 1973.

\section{Del radicalismo al giro conservador}

La última etapa abordada por nuestro autor comenzó en 1975 y solo la pudo analizar hasta fines de los años ochenta. Sin embargo, quienes lo conocimos y tuvimos la oportunidad de dialogar con él, podemos afirmar que probablemente hubiera definido una etapa mucho más conservadora a partir del nombramiento de Juan Luis Cipriani como arzobispo de Lima en $1999^{18}$. De hecho, en un trabajo presentado en el año 2000, Klaiber estableció en uno de los parágrafos de su texto: “el viraje conservador (1988-?)" (2000, p. 101). Ese proceso en el Perú estuvo marcado por la elección de Ricardo

17 En Bolivia, el arzobispo de La Paz, Jorge Manrique, declaró que no existía "conflicto entre el cristianismo y el neo socialismo" (Klaiber, 1997a, p. 209).

18 En sus conversaciones era más que notoria su distancia con el arzobispo y luego cardenal. Este enfrentamiento se expresó, entre otros hechos, en la lamentable decisión del arzobispo que aprovechando su cargo de canciller de la PUCP le prohibió desde el 2010 celebrar misa en la capilla de la universidad. En ese tiempo, mi oficina estaba frente a la del padre Klaiber y junto con otros colegas fuimos testigos del dolor que le causó esa injusta decisión. En una entrevista, Klaiber afirmó que con el arzobispado, Cipriani "ha fomentado pasos atrás con respecto a los cambios en la Iglesia. Se ha vuelto a proyectar la imagen de que aún se mantienen vínculos con los grupos de poder" (2006a, p. 63). 
Durand Flores S. J. como presidente de la Conferencia Episcopal Peruana. Flores, conocido adversario de teología de la liberación, fue elegido luego de que el cardenal Landázuri no reunió los votos necesarios para ser nombrado presidente. Otra clara señal del camino conservador fue la separación de las religiosas y los religiosos en el Instituto Superior de Estudios de Estudios Teológicos, que se produjo por mandato de Roma en 1987 (p. 103). Un tercer factor fue el conservadurismo de algunos obispos, especialmente en Ayacucho, epicentro de la violencia. Los obispos Fernando Richter Fernández-Prada y Juan Luis Cipriani fueron reactivos a los DH, especialmente el último de ellos (p. 194).

Con el fin de la primera fase del gobierno militar en 1975 y el nuevo presidente general Francisco Morales Bermúdez, comenzó un conocido viraje del gobierno hacia la derecha, mientras que el movimiento popular reaccionaba en contra de la crisis y obligaba a los militares a abandonar el poder por medio de la convocatoria a una asamblea constituyente y las elecciones presidenciales de 1980. El fracaso del experimento revolucionario-reformista llevó a la Iglesia a concentrarse más en su labor pastoral para atender las necesidades educativas, sociales y de dignidad de los pobladores, y dejar en segundo plano la lucha por un orden social más justo, apostando por un combate de largo plazo. A ese proceso Klaiber lo denominó "la Iglesia social-pastoral" (1996, p. 58), un periodo en que el enfrentamiento entre grupos progresistas y conservadores en el interior de la Iglesia se intensificó. Fue también el tiempo en que se amplió la noción de un catolicismo centrado en los problemas familiares y juveniles. Klaiber reconoce que esas propuestas más tradicionales tuvieron la importancia de renovar los lazos comunitarios de la liturgia, lo que permitió una integración de lo afectivo-espiritual con lo social (p. 60). La Iglesia peruana, de corte progresista antes de los años ochenta, sufrió un problema agudo: la escasez de vocaciones locales. De poco menos de 2300 religiosos, cerca del 60\% eran extranje- 
ros, mientras que de las 4835 religiosas, $42 \%$ también eran extranjeras, lo cual, de acuerdo con Klaiber, revela una Iglesia “misionera” (1997a, p. 251). Todo eso se acentuó con el neoconservadurismo de los años noventa.

La fase conservadora de la Iglesia, fechada a partir de 1975 por Klaiber, tiene uno de sus mejores ejemplos en los casos chileno y argentino. Luego del golpe de Estado de Pinochet, la Iglesia se apoyó en la vertiente conservadora de la religión, retomó el patronazgo de la Virgen del Carmen y señaló que el golpe tuvo como objetivos, entre otros, acabar con las herejías y con la confusión que reinaba en el país (p. 87). La iglesia chilena estaba internamente tan dividida como la sociedad, siete de los obispos eran conservadores, once se encontraban em el centro y doce eran progresistas ${ }^{19}$. Por lo menos seis de ellos apoyaron el golpe, lo cual impidió una reacción institucional; además, no se afectó fuertemente a los religiosos y religiosas en la represión inmediata. Salvo los 70 miembros de Cristianos por el Socialismo, quienes tuvieron que abandonar el país, tres curas fueron torturados y asesinados, y un cuarto desaparecido. La reacción del cardenal Silva fue mesurada, pero fundó el Comité de Cooperación para la Paz, precursora de la Vicaría de la Solidaridad (1976), la cual se enfrentó a la dictadura. La defensa de los DH le costó a la vicaría víctimas en su propia organización, hasta que en 1983 el arzobispo de La Serena, Juan Francisco Fresno, conocido por su conservadurismo, reemplazó a Silva como arzobispo de Santiago. A pesar de ese hecho y de la actitud conciliadora de Fresno, el recrudecimiento de la represión contra políticos de la DC y en contra de los movimientos de resistencia, nuevamente generó tensiones entre la Iglesia y la dictadura. Más allá de las distancias entre Silva y Fresno, este último tuvo

19 Las divisiones entre grupos de religiosos radicales y conservadores fueron muy frecuentes en América Latina, por ejemplo, en el caso boliviano (Klaiber, 1997a, p. 209). 
el mérito de continuar las políticas de su antecesor. Incluso Fresno fue muy importante para lograr el camino de retorno hacia la democracia, iniciado con el Acuerdo Nacional para la Transición a la Plena Democracia (1985), del cual fue uno de sus promotores. A pesar de la negativa de la dictadura, este documento, junto con la visita del papa Juan Pablo II en 1987, contribuyeron a que el gobierno tome la decisión de convocar al plebiscito en 1988 y, finalmente, iniciar el camino de retorno a la democracia.

Un camino similar se observó en la Iglesia boliviana, la cual reaccionó en contra de la dictadura de Hugo Bánzer, especialmente cuando su régimen se tornó más represivo y afectó a religiosos y religiosas (Klaiber, 1997a, p. 212) ${ }^{20}$. El enfrentamiento más serio entre la Iglesia y el gobierno fue la huelga de hambre de 1977 en protesta por la represión y la exigencia de la liberación de los presos políticos, la cual fue apoyada por el arzobispo Manrique. En esa protesta participaron algunos religiosos, quienes junto con el apoyo masivo de la población lograron el triunfo de sus demandas. La tensión aumentó con el secuestro, tortura y asesinato del sacerdote jesuita Luis Espinal, muy posiblemente ejecutado por fuerzas paramilitares de derecha.

El caso argentino muestra el apoyo de la Iglesia a un golpe militar de derecha. Ese apoyo se comenzó a gestar tiempo atrás, claramente desde el golpe militar en contra de Juan Domingo Perón en 1955 y el gobierno dictatorial de Juan

146 Carlos Onganía (1966-1970). Este último tuvo una política de contención en contra del radicalismo cultural y político, y consagró a la nación al Inmaculado corazón de María en 1969. Al mismo tiempo se desarrolló un intenso radicalismo político de extrema derecha e izquierda. Un conjunto de religiosos, muchos de ellos trabajadores en las villas mi-

20 Véase también Klaiber (1993). 
seria, el equivalente de los pueblos jóvenes, optaron por el socialismo y luego por el peronismo radical. Eso trajo como consecuencia que luego del golpe de Estado liderado por el general Jorge Videla, fueran víctimas de persecución, tortura, muerte y desaparición. La jerarquía eclesiástica más conservadora apoyó abiertamente el golpe de Estado, especialmente el vicario castrense y presidente de la Conferencia Episcopal Argentina, Adolfo Tortolo. La Iglesia no adoptó una política de confrontación pública contra el régimen; manifestó su descontento y preocupación por medio de mensajes privados, particulares y visitas (Klaiber, 1997a, p. 135). Esa actitud ambigua es muy criticada por Klaiber, quien considera que al no tomar una actitud resuelta en contra de las violaciones de DH, "sus acciones contradecían sus palabras" (p. 137). Incluso varios obispos no ocultaban su simpatía por los militares y criticaban a sus familiares por defender a sus hijos "descarriados por las drogas que fácilmente terminan siendo subversivos" (p. 137). La actitud timorata de la Iglesia es mucho más incomprensible porque la institución fue golpeada fuertemente por la represión, como el asesinato del padre Carlos Mugica y otros religiosos, entre ellos el obispo Enrique Angelelli en 1976.

En América Latina, hacia fines del siglo confluyeron dos legitimidades que permiten la vigencia de la Iglesia; la primera de ellas, de fondo tradicional proviene de la importancia y reconocimiento de la religión; la segunda, se basa en su defensa de los DH y la democracia (p. 19). Por ejemplo, aun las dictaduras más represivas se preocuparon por conseguir algún aval de la institución eclesial, lo cual no fue fácil. Salvo el caso de Efraín Ríos Montt en Guatemala, quien rompió con la Iglesia, los militares lograron el aval de obispos o autoridades religiosas, a juicio de Klaiber, de las fracciones ultraconservadoras; incluso de cristianos no católicos de las mismas características (p. 21). Los sectores progresistas se preocuparon por extender su solidaridad y protección a los 
perseguidos y a las víctimas de la represión, convirtiendo a la Iglesia en la principal defensora de las personas afectadas por el terror estatal y enfrentándose a los gobernantes, como ocurrió en Brasil a mediados de los años sesenta.

Sin embargo, Klaiber, a pesar de ser religioso pero fiel a sus principios, reconoce que la Iglesia latinoamericana se enfrentó a limitaciones a veces insalvables. La primera de ellas, y de la cual fue testigo y víctima, fueron los cambios en las políticas provenientes de Roma. Así, reconoce que desde el nombramiento de Juan Pablo II en 1978 comenzó un "cambio conservador con respecto a la política de sus antecesores. Sobre todo, los nombramientos episcopales recaían en hombres menos progresistas y, en algunos casos, de tendencia integrista, preocupados por sobre todas las cosas en mantener la unidad y fidelidad de la Iglesia, casi a cualquier costo" (p. 31). Eso significó el desarrollo de una política que no continuó, por el contrario, en algunos casos desmontó la intervención de la Iglesia en favor de los DH. Eso se expresó en los enfrentamientos internos en la Iglesia, entre aquellos que defendían las medidas represivas por sus objetivos de evitar el radicalismo socialista y comunista y quienes denunciaban la violación de los $\mathrm{DH}$. Sin embargo, esa lucha sí sirvió finalmente para unificar en algunos momentos específicos a la institución. Por ejemplo, en el caso del Brasil, si bien el gobierno buscó el apoyo de las jerarquías eclesiásticas, algunas de las cuales avalaron las medidas represivas, en 1969 los obispos publicaron un pronunciamiento en el que condenaban el marxismo, pero al mismo tiempo, también criticaban la visión individualista del capitalismo. Especialmente, cuestionaron la doctrina de seguridad nacional por permitir la violación de DH (p. 57). Eso no dejó a la Iglesia a salvo de la represión de los gobiernos militares. En Brasil, entre 1968 y 1973 se detuvo y procesó a no menos de 100 sacerdotes por motivos políticos; cifra que se elevó a lo largo de la década de 1970. Además, el compromiso de la Iglesia con los derechos 
de las mayorías, como ocurrió también en el Perú, llevó a que la institución apoye las huelgas en contra de los militares brasileños. La Iglesia brasileña calificada por Klaiber como una de las más progresistas del mundo fue muy afectada por los cambios impuestos por el papado de Juan Pablo II, interesado en contener los avances de la teología de la liberación, lo cual se tradujo en un neoconservadurismo.

Klaiber no constriñe su estudio al ámbito sudamericano. En el caso centroamericano aborda uno de los hechos más dramáticos con relación a los DH: las matanzas en El Salvador. Se calcula que medio millón de personas fueron desplazadas por la violencia, una cantidad similar huyó del país y alrededor de 80.000 mil personas murieron en la guerra civil, más o menos el 1,6\% de la población total ${ }^{21}$. La violencia, de raíces profundas, se acrecentó ante la negativa de las élites y militares de reformar el país, a pesar de los reclamos de la Federación Cristiana de Campesinos Salvadoreños y la Unión de Trabajadores del Campo, organizaciones que se enfrentaron a una dura represión por parte del gobierno y paramilitares en los ańos setenta. A esos grupos se sumaron las guerrillas de liberación, combatidas por el gobierno salvadoreño con apoyo norteamericano. En ese conflicto, de los más brutales de la historia latinoamericana contemporánea, se produjo el lamentable asesinato de monseñor Arnulfo Romero, uno de los defensores de los DH en El Salvador, y quien había denunciado los asesinatos de campesinos por parte de los militares y paramilitares. La Iglesia salvadoreña, no muy grande, contó con el apoyo de la Universidad Centroamericana José Simeón Cańas, fundada por los jesuitas en 1965, la cual se convirtió pronto en objeto de críticas por su progresismo. Luego del asesinato de Romero, su sucesor, Arturo Rivera Damas, como ocurrió en otros casos, trato de mediar entre

21 El equivalente con el Perú actual sería de poco menos de medio millón de personas. 
las partes en conflicto al mismo tiempo que fundó organizaciones para denunciar e investigar las violaciones de $\mathrm{DH}$. Por otro lado, a diferencia de otros casos, el Frente Farabundo Martí para la Liberación Nacional era un grupo guerrillero cercano a la Iglesia progresista, lo cual facilitó la mediación de la institución eclesial. Un caso similar se produjo en $\mathrm{Ni}$ caragua, donde la guerrilla sandinista estuvo muy cerca de la Iglesia progresista, lo que motivó acciones represivas por parte del gobierno.

Un balance que se puede hacer de la reflexión de Klaiber acerca de la Iglesia es que esta muestra las contradicciones y tensiones de la sociedad que la alberga. En todos los casos mencionados, en la institución eclesial convivían sectores progresistas, seguidores del Concilio Vaticano II y de Medellín, junto con otros denominados integristas que defendían la unidad de la Iglesia, el orden y el rechazo a los acuerdos de Vaticano II y de Medellín, y concebían al progresismo católico como marxista, comunista o socialista, incompatible con el catolicismo. Esa división interna permitió, al menos inicialmente, obtener apoyo de los golpistas para derrocar gobiernos que, en muchos casos, pretendían aplicar reformas progresistas. Sin embargo, una vez en el poder, era usual que esas dictaduras aplicaran políticas represivas que violaron constantemente los $\mathrm{DH}$, lo que causó que las disidencias internas de la Iglesia redujeran un poco su enfrentamiento a los gobiernos. Empero, tampoco esa defensa fue común en toda la jerarquía eclesiástica; un sector muy conservador consideró que los golpes de Estado y sus políticas posteriores eran la única manera de salvar a sus respectivas naciones.

La importancia social de la Iglesia se revela en su capacidad de albergar, proteger y promover a diversos movimientos civiles de protesta, de cambio o de denuncia en contra de la violación de los $\mathrm{DH}$, lo que contribuye decisivamente a la transformación de la realidad. 


\section{La Iglesia peruana y Sendero Luminoso}

Desde el punto de vista social, la historia que elabora Klaiber de la Iglesia peruana en tiempos de la violencia tiene aspectos muy interesantes ${ }^{22}$. Por ejemplo, considera que Sendero Luminoso (SL) en su relación con la Iglesia se asemeja mucho más a las dictaduras de derecha que a movimientos de izquierda de América Latina, debido a los asesinatos de religiosos, religiosas y catequistas. De acuerdo con la opinión de Klaiber, opinión luego retomada por la Comisión de la Verdad y Reconciliación (CVR), en las zonas en las que la Iglesia logró desarrollar una pastoral comprometida con la mayoría de la población SL tuvo muchas más dificultades para tomar los territorios bajo su control. "En cambio, en las partes del Perú donde la Iglesia no había experimentado un cambio de mentalidad, Sendero encontró un campo más fértil" (1997a, p. 238). Su posición es que SL con su carácter dogmático no se acercó a la Iglesia y la consideraba un obstáculo para sus planes. Sin embargo, en Ayacucho, de acuerdo con Klaiber, no fue necesario enfrentarse a ella porque con su conservadurismo extremo no atraía a los más jóvenes ${ }^{23}$. Cuando SL ocupaba zonas en las que la Iglesia progresista había avanzado, la atacaba duramente ${ }^{24}$. Por esa razón, en otras zonas del Perú SL dinamitó obras de la Iglesia en la sierra sur y asesinó a religiosos y religiosas, en cierta forma, eso fue un macabro reconocimiento de la importancia social de la Iglesia.

22 Véase también Klaiber (2005a).

23 Los obispos de Ayacucho de ese tiempo fueron Federico Richter Fernández-Prada (1979-1991) y Juan Luis Cipriani (1991-1999). Ambos son considerados como muy conservadores.

24 En su análisis, Klaiber incluye a los grupos evangélicos, que fueron también víctimas de la violencia de SL, especialmente por su influencia en las comunidades de la sierra y selva. Asimismo, sufrieron mucha violencia por parte de las fuerzas del orden, con casos que demuestran los abusos que se dieron en ese tiempo. 
En Cajamarca, durante el obispado de José Dammert de 1962 a 1992, las condiciones sociales del campesinado, menos deprimido económicamente que en el sur, contribuyeron a la aparición de las rondas campesinas en principio como una reacción en contra del abigeato y luego fueron usadas como autodefensa en contra de SL. Klaiber reconoce la labor del obispo, quien aplicó los principios de Vaticano II, formando centenares de agentes pastorales que sirvieron de parachoques para evitar la difusión de SL. Otro caso similar es el de Puno, con el añadido de las organizaciones políticas que contribuyeron a obstaculizar el avance de SL. En esa región fueron esenciales las órdenes religiosas como los Maryknoll y los Sagrados Corazones y el apoyo de obispos como Luciano Metzinger y Luis Vallejos. En ese sentido, fue importante la creación del Instituto de Pastoral Andina, con el objetivo de preparar a los agentes pastorales. Eso llevó a que la Iglesia de la zona, desde los ańos sesenta, apoyara el proceso de reforma agraria, legitimando la lucha de los campesinos en favor de la redistribución de la propiedad. Como señala Klaiber, eso produjo una "Iglesia viva" que sirvió de dique contra el avance de SL. La respuesta de SL fue reconocer que esa acción de la Iglesia le era desfavorable. Eso motivó que los religiosos y religiosas unieran fuerzas con otras asociaciones para oponerse a la violencia de SL. En la selva peruana, la Iglesia también apoyó a las organizaciones locales, especialmente a partir de la labor de los misioneros; sin embargo, no contaron con tanto apoyo, pues la enorme extensión del espacio y otras dificultades determinaron el retiro de varias misiones.

Todos esos hechos llevaron a que la jerarquía se preocupara mucho más de la violencia, la violación de los $\mathrm{DH}$ y la necesidad de recuperar la paz. Empero, como en otras realidades de América Latina, existían disensiones internas en la Iglesia peruana. Un grupo de obispos veía el problema fundamentalmente como un problema policial y militar, lo que impedía un punto de vista homogéneo. Además, la polémica 
acerca de la teología de la liberación afectó la unidad de la Iglesia peruana. A pesar de todos esos problemas, la Conferencia de Obispos Peruanos se manifestó en contra de la violencia en varias oportunidades. Otra dimensión social de la Iglesia fue la fundación de la Coordinadora Nacional de Derechos Humanos en 1985, conformada por varias instituciones vinculadas con la institución eclesiástica. Su papel fue muy importante en la convocación de marchas de protesta contra la violencia, lo que contribuyó a la derrota de SL. La preocupación por los DH también se muestra en la activa participación de la Iglesia en la CVR.

\section{Religión, justicia social, revolución y ciudadanía}

Con la misma importancia con la que abordó la historia de la Iglesia, Klaiber estudió los movimientos sociales, las revoluciones y su relación con la religión. Su reflexión historiográfica comenzó a deslizarse, entre 1976 y principios de la década de 1980, del estudio del aprismo al papel de la Iglesia en el Perú, el racismo, la justicia y los movimientos sociales. Su tesis doctoral de 1976 (editada en inglés en 1977, en español en 1980 y ampliada en la edición de 1988) ofrece una buena perspectiva de esos cambios $^{25}$.

Su estudio de las rebeliones indígenas de fines del siglo XIX es un ejemplo de ese proceso personal. Su análisis comienza reconociendo las diferencias entre los diversos grupos indígenas a lo largo del territorio peruano, cuya ubicación social y económica se relacionaba directamente con la propiedad: "simplificando algo, diríase que la estructura social de la sierra y del campo tendía a corresponder con la relación de cada uno a la tierra” (1988 [1980], p. 62). Esa afirmación bien

25 Un adelanto de estos temas se publicó en el primer número de la revista Histórica (Klaiber, 1977). 
podría ser relacionada con el pensamiento mariateguista, el cual Klaiber conocía perfectamente ${ }^{26}$, quien señaló que el problema del indio era su acceso a la tierra. La percepción negativa de los indígenas se agravó con el positivismo de fines del siglo XIX y se le consideró responsable del atraso y decadencia de la nación, definido como "flojo, exagerado, mentiroso y ladrón" (p. 64), ocioso por naturaleza y enemigo acérrimo de los blancos, totalmente reactivo a la civilización occidental. Esa percepción justificaba la explotación a la que era sometido, la cual fue cuestionada por las rebeliones de indígenas de fines del siglo XIX.

En la rebelión de Huancané (1866-1868), producto del intento de cobrarle el tributo a los indios, el obispo de la recientemente creada diócesis de Puno, Juan Ambrosio Huerta, cumplió un papel importante. Su actitud fue de mediador a pedido de la población, mientras las autoridades políticas del departamento decidieron reprimir a la población. Los indígenas reaccionaron ante los atropellos y muertes, denunciaron la situación de injusticia que vivían cotidianamente y agradecieron la intermediación del obispo Huerta. Lamentablemente, el conflicto se reavivó con el levantamiento del coronel Juan Bustamante y su enfrentamiento con el coronel Andrés Recharte, que dejó el saldo de 72 indios asfixiados por este último en venganza por ser seguidores de Bustamante $($ p. 64) 27 .

El intento del obispo de Ayacucho Juan José Polo de mediar en el levantamiento de Huanta en 1896 fue trágico, no fue reconocido por las partes en conflicto y fue asesinado. Las causas de esa rebelión fueron el aumento del impuesto a la sal y el

26 Véase su análisis del pensamiento del Amauta en Klaiber (1980, pp. 109134).

27 Otro caso interesante es la rebelión de Huánuco (1895), que parece que contó con el apoyo del cura Simeón Zeballos. 
retiro de circulación de la moneda feble boliviana, sumados a los conflictos entre familias de la zona que usaban a los indios como parte del conflicto. Los indios atacaron Huanta y asesinaron a las autoridades, protesta que se extendió a otras localidades de la sierra central. Ante tal emergencia, el gobierno decidió reprimir las revueltas como una forma de escarmentar a los rebeldes de todo el país. En el movimiento huantino tuvo importancia la participación del cura Pedro Betalleluz, quien intentó mediar entre los rebeldes y el ejército, pero fue considerado por estos últimos como aliado de los indios. Sin embargo, se disculpó con el coronel Domingo Parra y alegó que actuó presionado por los rebeldes, especialmente por los caceristas que apoyaban el movimiento (p. 72).

Si bien en varios casos los curas y obispos apoyaron las protestas de los indios, en otros casos se colocaron del lado del gobierno. En Puno, en el levantamiento de 1895-1897, las causas apuntaban al aumento del precio de la sal y los abusos de las autoridades civiles y religiosas. Los militares encargados de la pacificación de los sublevados recurrieron a la presencia de los sacerdotes con el objetivo de disuadir a los indios, gracias al conocimiento de los religiosos del aymara. De acuerdo con Klaiber, los casos más típicos fueron como este último, en el que los represores utilizaron a la Iglesia para lograr sus objetivos. Sin embargo, "en otros casos contados, el clero abogó abiertamente en favor de los indios, hasta llegar a arriesgar la vida para protegerlos contra el ejército: tal fue el caso notable del obispo Huerta, de Puno" (p. 74).

Huaraz (1885) fue testigo de una de las rebeliones más importantes del siglo XIX. En ese lugar, cerca de 40 alcaldes indios elevaron un memorial de protesta al prefecto Francisco Noriega por los trabajos forzados, el estanco de la sal y la contribución personal. El prefecto actuó de forma violenta, rechazó el memorial y encarceló a Pedro Pablo Atusparia, uno de los alcaldes, a quien torturó para que confiese ser 
autor del escrito. Luego de encarcelar a más alcaldes, la reacción de los indios se tornó violenta y atacaron la ciudad de Huaraz. El levantamiento, con el liderazgo de Atusparia, se extendió a otros pueblos de la región y fue debelada un par de años después. De acuerdo con los testimonios de la época, durante el control de los rebeldes de la ciudad, se celebró la Semana Santa con gran fe y pompa, con la participación del clero local. Uno de los personajes del levantamiento fue el padre Fidel Olivas Escudero, natural de Huari, altamente estimado por blancos e indios. Su labor fue la de mediador, intentó salvar infructuosamente de la destrucción total a Yungay intercediendo por sus habitantes ante Atusparia y logró moderar en algo la ocupación (p. 84) ${ }^{28}$.

Para Klaiber, lo importante es que esos hechos muestran la legitimidad de la Iglesia en los sectores más populares; su religiosidad no fue motivo para no rebelarse. Apareció "una profunda contradicción entre la creencia religiosa, el progreso y la justicia social... los indios habían llegado a experimentar y a aceptar como normal una compatibilidad entre su catolicismo popular y su lucha por la justicia social" (p. 85 ). Esta idea es fundamental en la evolución historiográfica de nuestro autor, pues lo llevó a plantearse la relación histórica entre religión y justicia social. A principios de los años ochenta, Klaiber publicó una reflexión acerca del Señor de los Milagros en la revista Debate (noviembre 1981), reeditado en Klaiber (1998), la cual comienza con la célebre cita de Karl Marx de la religión como opio del pueblo. Su respuesta a esa afirmación es que ella también fue capaz "de dinamizar a todo un pueblo en su lucha por conseguir la libertad política o económica” (1998, p. 3). Su ejemplo es el culto al

28 A pesar de estos casos de intervención de religiosos a favor o, al menos, de mediación en los conflictos, Klaiber reconoce que existieron muchos otros casos de mal comportamiento de sacerdotes, como la seducción de mujeres, enriquecimiento, abuso, etcétera (Klaiber 1988 [1980], p. 64). 
Señor de los Milagros, que comenzó como una devoción vinculada con los esclavos coloniales y se extendió poco a poco al resto de la sociedad. Su culto, de acuerdo con Klaiber, se presta para un análisis "desde la perspectiva de la teología de la liberación" (p. 6). Por ejemplo, al principio fue rechazado por la jerarquía eclesiástica, la que incluso trató de destruir la imagen en 1671. Klaiber sostiene que fue

un culto que nació de un pueblo vencido. El artista que pintó la imagen es desconocido, por lo tanto, simboliza el anonimato de los pobres. El Cristo de la imagen, que "desafía" a las autoridades e "insiste" en su derecho a existir, es símbolo del pueblo mismo. De ahí en adelante, el Cristo de los esclavos se convierte en propiedad del pueblo y expresión principal de su fe, no los distintos "Cristos" oficiales impuestos desde arriba. (1998, p. 8)

Klaiber reconoce, con el lenguaje de la época, que el culto tiene la importancia de mezclar a diversas "razas", con un lenguaje festivo y místico, pero otorgando "un lugar privilegiado para los de raza negra” (p. 10). En palabras de hoy, les permitió a los africanos y afrodescendientes colocarse en el centro de la religiosidad popular, legitimándose. Este culto expresó la voluntad popular, de acuerdo con nuestro autor, y especialmente defendía "su derecho de creer o de tener fe en algo, porque sin ella pierde su ánimo para sobrevivir y la libertad interior necesaria para soportar y cuestionar el sistema" (p. 10). Incluso, Klaiber retoma las ideas de Mariátegui acerca de la religiosidad popular, en las que destacó el carácter paciente de la fe de los sectores populares ${ }^{29}$. Klaiber señala que Mariátegui tuvo razón al señalar que, rechazando el racionalismo extremo del marxismo que él también combatía, "sin una fe una persona no puede vivir ni crear y, sin

29 Para una reflexión de Klaiber acerca de la religiosidad popular indígena y sus debates, véase (1980, pp. 104-108). 
una fe colectiva, un pueblo no puede levantarse" (p. 11) $)^{30}$. El párrafo final de su ensayo retoma y parafrasea la cita de Marx mencionada al inicio:

En conclusión, podemos afirmar, parafraseando a Marx, que la gran procesión que sale todos los ańos en octubre, así como todos los demás actos religiosos importantes para el pueblo, representan, por una parte, "la expresión de la miseria real, y, por otra parte, la protesta contra la miseria real... el suspiro de la criatura agobiada por la desgracia, el alma de un mundo sin corazón..., el espíritu de una época sin espíritu”. Pero, no es “opio”. El Señor morado significa también, consuelo, fortaleza y esperanza para un pueblo en busca de una gran liberación. (Klaiber 1998, p. 11). (El subrayado es mío).

Como se puede notar, Klaiber reconoce que la búsqueda de liberación de los pueblos colonizados de América Latina es histórica. Esa perspectiva de principios de los ańos ochenta comenzó a ser explorada por este autor desde fines de los años setenta. Si bien en su tesis doctoral y sus ediciones de 1976 y 1980 hay indicios de esas ideas, por ejemplo, la mención en la literatura indigenista de la similitud del sufrimiento de Cristo con el abuso en contra de los indios (1980, pp. 180-181), fue a partir de 1978 que comenzó a relacionar la doctrina cristiana, la religión y la historia social. Su primer trabajo "diferente" es el estudio del racismo durante la guerra del Pacífico (1879-1883).

El vector que lo llevó a interesarse en la historia social más allá de la Iglesia fue el racismo. Si bien en sus trabajos anteriores había tocado el tema desde la posición de las élites eclesiásticas, intelectuales y políticas, lo hizo para comprender la evolución de la Iglesia y su historia, como uno de los factores que ella compartía con el resto de la sociedad. En su texto Los "cholos" y los "rotos": actitudes raciales durante la guerra

30 Véase también Klaiber (1980, pp. 118-119). 
del Pacifico (1978), Klaiber establece cómo los estereotipos acerca de los indios peruanos y bolivianos y sus diferencias con la población considerada anglosajona y blanca de Chile fueron usados por los vencedores para explicar el resultado de la guerra. La explicación de esta actitud, de acuerdo con el autor, se puede atribuir, al menos parcialmente, a la "pérdida del sentido de igualdad universal de todos los hombres, influida en parte por la reforma protestante y el calvinismo en particular" (1978, p. 25). Este punto de partida, más allá de su validez, lo llevó a considerar al cristianismo católico como más cercano a las luchas históricas por la justicia social e igualdad en América, pero no desde la perspectiva de las autoridades eclesiásticas, sino desde la práctica de los pueblos, tal como la teología de la liberación lo sostuvo en la década de los años setenta.

El escenario histórico que abordó en esa búsqueda fue el proceso de independencia. Como se evidencia en su Independencia, Iglesia y clases populares (1980), su preocupación consistió en ir más allá de las jerarquías eclesiásticas, de origen peninsular y criollo, de actitud ambigua frente a la Independencia. Así, reconoce tres niveles de análisis: "un nivel de jerarquía, otro del clero y un tercero que correspondía a los estratos populares. Estos tres niveles estaban unidos por los mismos símbolos del cristianismo, pero cada grupo daba distintas interpretaciones a los símbolos, según su propia perspectiva social y política" (1980, p. 15). Si bien como institución, la Iglesia no manifestó su apoyo a la causa patriótica, sí se tiene conocimiento de la participación del clero en ese bando, especialmente de aquellos religiosos sensibles a los abusos a los cuales estaban sometidos los indios. Sin embargo, la institución estaba conformada tanto por miembros de las élites como sectores populares y en su interior se reflejaron las mismas tensiones sociales. Por eso "fue elitista y popular al mismo tiempo" (p. 17). En algunos movimientos, como el del Cusco en 1814, la participación del clero local fue noto- 
ria (p. 45); mientras que el arzobispo de Lima Bartolomé Las Heras, firmante del Acta de Independencia, y otros obispos fueron obligados a abandonar el Perú, algunos de ellos por sus evidentes simpatías realistas (p. 51). ${ }^{31}$

Klaiber encuentra en Túpac Amaru y su rebelión un ejemplo de la importancia del discurso religioso para comprender los movimientos de protesta. El rebelde se basó en las enseñanzas cristianas, especialmente del viejo testamento, para sustentar su levantamiento. En una carta dirigida al visitador José Antonio de Areche, comparó su rebelión con la causa de Israel ante el faraón, e incluso la lucha de David frente a Goliat (p. 19). La diferencia es que los indios del virreinato lucharon frente a varios faraones: corregidores, oficiales del rey, etcétera. Todos los mencionados tienen mayor responsabilidad que otras figuras en la historia porque, supuestamente, eran católicos y deberían defender la justicia y la verdad. Así, estos serían cristianos superficiales, "ateos prácticos", como los califica Klaiber en su ensayo titulado Religión y justicia en Túpac Amaru" (1982); mientras que los indios y Túpac Amaru, por su defensa de la justicia serían "cristianos anónimos", personas que sin reclamarse abiertamente cristianos o, en tiempos más recientes, sin ser tales, se encuentran más cerca de las enseñanzas de Cristo (1982, pp. 182-183).

Precisamente en su artículo de 1982, dedicado a Túpac Amaru, revela con mayor claridad la relación entre el cristianismo y la liberación. La defensa del inca, citando la Biblia en la carta dirigida a Areche poco antes de ser capturado, revela su decisión de presentarse como un buen cristiano, cuestionando la campaña por presentarlo como un traidor e impío, como lo calificó al excomulgarlo el obispo del Cusco, Juan Manuel Moscoso y Peralta. Si bien la masa de rebeldes atacó iglesias y asesinó curas, las órdenes de Túpac Amaru buscaron

31 Véase también Klaiber (1987a y 2001). 
evitar esas acciones, conminando a los indios a respetar los templos y a los religiosos. Incluso algunos religiosos simpatizaron inicialmente con su causa (Klaiber, 1983, p. 174). Sin embargo, la jerarquía lo tildo de "hipócrita", desconociendo su cristianismo.

Túpac Amaru se presentó como respetuoso de la Iglesia y su doctrina, comparando, como se mencionó, su levantamiento con hechos del Antiguo Testamento, como la liberación de los judíos liderada por Moisés. Así, de alguna manera Túpac Amaru se propone como liberador de los indios, posición que fue rechazada por la jerarquía eclesiástica por su carácter mesiánico. Si bien el rebelde nunca afirmó que había recibido esa misión como parte de un mensaje divino, intentó presentar su causa como justa y recta ante los ojos de Dios (Klaiber, 1982, p. 180). Así, los corregidores y sus secuaces serían los verdaderos impíos y traidores, acusándolos de ateos, calvinistas y luteranos. Por esas razones, Klaiber señala que en la teología contemporánea pueden ser considerados “ateos prácticos”.

Esta interpretación vincula las preocupaciones religiosas de Klaiber y su práctica como historiador. Como hemos visto, una de sus líneas de investigación fue la historia de la Iglesia y su defensa de los derechos humanos, incluso antes de que estos se definan como tales. La institución desde su llegada a América Latina, según Klaiber, siempre tuvo personajes que lucharon por la justicia y estaban en contra del "ateísmo práctico", como es reconocido en las conferencias de Medellín (1968) y Puebla (1979). De acuerdo con su interpretación, "el sentido de estos documentos es bastante claro: lo que debería distinguir la vida y la fe de un cristiano moderno es una inquietud por la justicia social y los derechos humanos" (p. 183). En ese sentido, la lucha de Túpac Amaru se inscribe en una tradición de continuidad "entre el grito de Las Casas y la lucha moderna de muchos cristianos en América Latina en favor de la justicia y los derechos humanos" (p. 185). 


\section{Conclusiones}

Los matices de la historiografía de Klaiber son muchos. En este incompleto balance hago notar algunos de ellos, desde su perspectiva como hombre de fe e intelectual. A lo largo de su dilatada carrera como historiador, desde su primera investigación (1968) hasta la póstuma (2016), siempre dejó constancia de esa doble mirada que logró hacer totalmente compatible.

Existe consenso en cuanto a su obra como historiador, considerada mesurada y objetiva, a pesar de que nunca ocultó ni negó su perspectiva como religioso. Pienso que la importancia de su trabajo reside en utilizar esa perspectiva que proviene de sus preocupaciones religiosas, del papel de la Iglesia de los jesuitas y de la religión en la sociedad. Indagó acerca de su relación con otros grupos sociales y su influencia en el cambio social y sus preguntas lo remitieron a otros temas, pero sin abandonar los ejes de su reflexión.

Hombre reservado y modesto, quienes lo conocimos lo recordaremos por su defensa de la Iglesia y de la universidad como institución de diálogo, crítica y libertad de pensamiento. Sin duda, su repentina desaparición dejó un gran vacío personal e intelectual difícil de llenar. Su originalidad, su dedicación y, especialmente, su honestidad son valores que continúan presentes, a pesar de que su cuerpo físico no está más con nosotros.

162

Recibido: 05 de enero de 2020

Aprobado: 18 de marzo de 2020

\section{Referencias bibliográficas}

GUIBOVICH, P. M.

(2014) In memoriam Jeffrey Klaiber Lockwood S. J. (19432014). Histórica, 38 (2), 147-150. 
HOBSBAWM, E. J.

(1998) Sobre la historia. Barcelona: Crítica.

KLAIBER, J.

(1968), The role of the Gonzalez Prada Universities in the development and formation of the Aprista Movement (Master Thesis of Arts in History). Loyola University, Chicago.

KLAIBER, J.

The Popular Universities and the Origins of Aprismo, 1921-1924. The Hispanic American Historical Review, 55 (4), 694-715.

KLAIBER, J.

Religion and Reform in Perú, 1824-1945 (Ph. D Thesis). Catholic University of America, Washington, D. C.

KLAIBER, J.

(1977a) Religión en revolución en los Andes en el siglo XIX. Histórica, 1 (1), 93-11.

KLAIBER, J.

(1977b) Religion and Reform in Perú, 1824-1976. Notre Dame: University of Notre Dame Press.

KLAIBER, J.

(1978) Los "cholos" y los "rotos": actitudes raciales durante la guerra del Pacífico. Histórica, 2 (1), 27-37.

KLAIBER, J.

Independencia, Iglesia y clases populares. Lima: Centro de Investigación Universidad del Pacífico.

KLAIBER, J.

(1981) La escasez de sacerdotes en el Perú: una interpretación histórica. Histórica, 5 (1) 1-19. 
KLAIBER, J.

(1982) Religión y justicia en Túpac Amaru. Allpanchis, 16 (19), 173-186. https://doi.org/10.36901/allpanchis. v14i19.868

KLAIBER, J.

(1983b) Los partidos católicos en el Perú. Histórica, 7 (2), 93111.

KLAIBER, J.

(1983c) The Catholic Lay Movement in Peru: 18671959. The Americas, 60 (2), 149-170. https://doi. org/10.2307/980764

KLAIBER, J.

(1987a) Independencia y ciudadanía. En A. Adrianzén (Ed.), Pensamiento político peruano (pp. 73-93). Lima: Desco.

KLAIBER, J.

(1987b) La pugna sobre la educación privada en el Perú 19681980: un aspecto del debate interno en la Iglesia católica. Apuntes, 20, 33-52. https://doi.org/10.21678/ apuntes.20.247

KLAIBER, J.

(1988a) Ética, abusos del poder y corrupción en el Perú. Una perspectiva histórica. En J. Klaiber (Ed.), Violencia y crisis de valores en el Perú. Trabajos interdisciplinarios (pp.177-196). Lima: Fondo Editorial Pontificia Universidad Católica del Perú

KLAIBER, J.

(1988b [1980]). Religión y revolución en el Perú, 1824-1988. Lima:

Centro de Investigación, Universidad del Pacífico.

KLAIBER, J.

(1990) Toward a New History of the Church in the Third World, International Bulletin of Missio- 
nary Research, 14 (3), 105-106. https://doi. org/10.1177/239693939001400302

KLAIBER, J.

(1993) The Catholic Church's Role as Mediator: Bolivia 1968-1989. Journal of Church and State, 35 (2), 351366. https://doi.org/10.1093/jcs/35.2.351

KLAIBER, J.

La Iglesia en el Perú. Su historia social desde la Independencia. Lima: Fondo Editorial Pontificia Universidad Católica del Perú.

KLAIBER, J.

Iglesia, dictaduras y democracia en América Latina. Lima: Fondo Editorial Pontificia Universidad Católica del Perú.

KLAIBER, J.

(1997b) Los años cincuenta: el contexto político y social. Enseñanza de la Historia, 16, 3-7.

KLAIBER, J.

El Señor de los Milagros: fe y liberación. En J. Klaiber, S. J y D. Irarrázaval, El Señor de los Milagros: devoción y liberación (pp. 3-11). Lima: Centro de Estudios y Publicaciones.

KLAIBER, J.

La Iglesia: 1930-1950 En F. Armas, La construcción de la Iglesia en los Andes (siglos XVI-XX) (pp. 493521). Lima: Fondo Editorial Pontificia Universidad Católica del Perú.

KLAIBER, J.

(2000) Iglesia católica y poder político en el siglo XX. En M. Marzal S. J., C. Romero y J. Sánchez (Eds.), La religión en el Perú al filo del milenio (pp. 87-108). Lima: 
Fondo Editorial Pontificia Universidad Católica del Perú.

KLAIBER, J.

(2001)

El Clero y la Independencia del Perú" En S. O’Phelan (Ed.), La Independencia en el Perú. De los Borbones a Bolivar (pp. 119-136). Lima: Instituto Riva Agüero, Pontificia Universidad Católica del Perú.

KLAIBER, J.

(2004a) Enfoque histórico sobre Haya de la Torre. Tipshe. Revista de la Facultad de Humanidades, 4 (4), 237-244.

KLAIBER, J.

(2004b) Peru's Truth Commission and the Churches. International Bulletin of Missionary Research, 28 (4), 178-179. https://doi.org/10.1177/239693930402800408

KLAIBER, J.

(2005a) Iglesia, religión y Sendero Luminoso. Ius et Veritas, 13 (25), 390-393.

KLAIBER, J.

(2005b) El miedo al APRA. En C. Rosas (Ed.), El miedo en el Perú. Siglos XVI al XX (pp. 257-264). Lima: Fondo Editorial Pontificia Universidad Católica del Perú.

KLAIBER, J.

(2006a) Derechos Humanos: una visión histórica. En E. Salmón (Coord.), Miradas que construyen. Perspectivas multidisciplinarias sobre los derechos humanos (pp. 1144). Lima: Fondo Editorial Pontificia Universidad Católica del Perú.

KLAIBER, J.

(2006b) Los aportes de la Iglesia Católica a la consolidación del sistema democrático. Entrevista al Jeffrey Klaiber S. J. Avanzada, 2, 65-67. 
KLAIBER, J.

(2007) Los jesuitas en América Latina, 1549-2000. 450 años de inculturación, defensa de los derechos humanos y testimonio profético. Lima: Fondo Editorial Universidad Antonio Ruiz de Montoya.

KLAIBER, J.

(2012) El Vaticano II y sus contextos. Pastores del Nuevo Milenio, 12 (23), 15-22.

KLAIBER, J.

(2016) Historia contemporánea de la Iglesia católica en el Perú. Lima: Fondo Editorial Pontificia Universidad Católica del Perú.

PORTOCARRERO, R.

(2015) Jeffrey Lockwood Klaiber, SJ (1943-2014). Hispanic American Historical Review, 95 (1), 135-139. https:// doi.org/10.1215/00182168-2836940

STEIN, S. y STEIN, B.

(1974) La herencia colonial de América Latina. México: Siglo XXI.

TORRES, C.

(1998-1999) Estudiar y luchar por la liberación nacional. Juventud y movimientos universitarios en la PUCP de los sesenta. Debates en Sociología, 23-24, 126-145. 